\title{
The incidence of adverse events in an Italian acute care hospital: findings of a two-stage method in a retrospective cohort study
}

Lorenzo Sommella ${ }^{1}$, Chiara de Waure ${ }^{2}$, Anna Maria Ferriero², Amalia Biasco ${ }^{2}$, Maria Teresa Mainelli Luigi Pinnarelli ${ }^{1}$, Walter Ricciardi ${ }^{2}$ and Gianfranco Damiani ${ }^{2^{*}}$

\begin{abstract}
Background: The promotion of safer healthcare interventions in hospitals is a relevant public health topic. This study is aimed to investigate predictors of Adverse Events (AEs) taking into consideration the Charlson Index in order to control for confounding biases related to comorbidity.

Methods: The study was a retrospective cohort study based on a two-stage assessment tool which was used to identify AEs. In stage 1, two physicians reviewed a random sample of patient records from 2008 discharges. In stage 2 , reviewers independently assessed each screened record to confirm the presence of AEs. A univariable and multivariable analysis was conducted to identify prognostic factors of AEs; socio-demographic and some main organizational variables were taken into consideration. Charlson comorbidity Index was calculated using the algorithm developed by Quan et al.

Results: A total of 1501 records were reviewed; mean patients age was 60 (SD: 19) and 1415 (94.3\%) patients were Italian. Forty-six (3.3\%) AEs were registered; they most took place in medical wards (33, 71.7\%), followed by surgical ones $(9,19.6 \%)$ and intensive care unit (ICU) $(4,8.7 \%)$. According to the logistic regression model and controlling for Charlson Index, the following variables were associated to AEs: type of admission (emergency vs elective: OR 3.47, 95\% Cl: 1.60-7.53), discharge ward (surgical and ICU vs medical wards: OR 2.29, 95\% Cl: 1.00-5.21 and OR 4.80, 95\% $\mathrm{Cl}$ : 1.47-15.66 respectively) and length of stay (OR 1.03, 95\% Cl 1.01-1.04). Among patients experiencing AEs a higher frequency of elderly ( $\geq 65$ years) was shown ( $58.7 \%$ vs $49.3 \%$ among patients without AEs) but this difference was not statistically significant. Interestingly, a higher percentage of patients admitted through emergency department was found among patients experiencing AEs (69.7\% vs $55.1 \%$ among patients without AEs).
\end{abstract}

Conclusions: The incidence of AEs was associated with length of stay, type of admission and unit of discharge, independently by comorbidity. On the basis of our results, it appears that organizational characteristics, taking into account the adjustment for comorbidity, are the main factors responsible for AEs while patient vulnerability played a minor role.

Keywords: Clinical risk, Hospital, Ordinary admission, Charlson index, Comorbidity

\section{Background}

Adverse events (AEs), referred to as healthcare delivering, have been defined as injuries that are caused by medical management rather than the underlying disease [1] and which result in death, life threatening illness, disability at the time of discharge, admission to hospital, or prolongation

\footnotetext{
* Correspondence: gdamiani@rm.unicatt.it

${ }^{2}$ Department of Public Health, Catholic University of Sacred Heart, L.go

Francesco Vito 1, Rome 00168, Italy

Full list of author information is available at the end of the article
}

of hospital stay [2-6]. Considering the complex nature of modern medical practice and the multitude of interventions delivered by now to each patient, a high rate of AEs might not be surprising, but if we only think of Hippocrates' warning "Primum non nocere", it is not acceptable at all. Moreover, the delivering of high standard quality of care would be a commitment for every healthcare organization because patient safety is a fundamental prerequisite to quality itself [7]. Nevertheless, AEs while receiving health care, even in technologically advanced hospital settings,

\section{Biomed Central}

(c) 2014 Sommella et al.; licensee BioMed Central Ltd. This is an Open Access article distributed under the terms of the Creative Commons Attribution License (http://creativecommons.org/licenses/by/4.0), which permits unrestricted use, distribution, and reproduction in any medium, provided the original work is properly credited. The Creative Commons Public Domain Dedication waiver (http://creativecommons.org/publicdomain/zero/1.0/) applies to the data made available in this article, unless otherwise stated. 
are still so disturbingly common that, in 2009, the World Health Organization recognised patient safety as a serious public health issue affecting countries at all levels of development. Indeed, reducing the incidence of patient harm is a matter for everyone involved in health care $[8,9]$. Since the 1970's, epidemiological studies highlighted high rates of AEs experienced during hospital stay, ranging from $3.7 \%$ up to $36 \%[1,10,11]$. Over the past 20 years, several studies, some of which nationwide, based on hospital records retrospective reviews, conducted in the USA [1,5], Canada [12,13], South America [14], Great Britain [6], Denmark [15], France [4], Germany [16,17], Spain [18,19], Sweden [20], Australia [21] and New Zealand $[22,23]$ have shown that the chance of a patient to experience an AE during hospitalization is still too high, ranging between $2.9 \%$ and $17 \%$. Furthermore, it was noted that approximately half of the AEs were preventable $[3,16,17]$. Several studies have analyzed predictors of AEs [3,4,14,17-19,24,25] such as emergency admission, surgical procedures, patient risk factors (age, gender, co morbidity etc.), length of stay, unit of discharge, organizational factors, human behaviors, and environmental causes. These predictors have been studied through different methods: cross sectional studies, prospective cohort, and retrospective cohort. Other studies $[3,14,26]$ in order to evaluate how much co morbidity conditions could influence health outcomes, have used the Charlson Index.

This study is aimed at the following: 1) counting AEs occurring in an Italian acute care hospital by a 2-stage review of hospital charts; 2) assessing organizational predictors for AEs as well as individual risk factors; 3 ) taking into consideration the Charlson Index as a potential tool to control for confounding related to comorbidity.

\section{Methods}

\section{Study design and setting}

A retrospective cohort study was conducted to examine the incidence of AEs in an Italian acute care hospital. The clinical records included in the study were selected at random starting from the electronic archive of the hospital discharges. The sample included inpatients of all ages, if they stayed $>24 \mathrm{~h}$ in the hospital and were discharged between the January 1, 2008 and December 31, 2008 (inclusive), day hospital discharges were not included. Inpatient care represented about $72 \%$ of the overall admissions in 2008. On the basis of these criteria, the sample comprised of 1,501 discharges, which represents the $7.3 \%$ of the overall inpatient admissions in 2008. All the hospital specialties were considered in the study in order to reflect the overall hospital practice. This study involved a two-stage sampling approach. Clinical records were analyzed with tools developed by Charles Vincent and colleagues [6]. The hospital clinical records were screened by two physicians (LP and $\mathrm{AB}$ ) with experience in clinical risk management. The reviewers were trained by a theoretical-practical training course that lasted two and a half days. In the first stage of the review process (modular revision form 1 - RF1 -), the reviewers screened the records using 16 explicit screening criteria indicating potential AEs, adapted by those of Vincent et al. To test the validity of the process of screening, the two reviewers independently examined the first $10 \%$ of clinical records, and they compared assessments to see if they were in agreement with the identification of one or more criteria and the selection of potential AEs. The remaining $90 \%$ of clinical records was equally distributed by the two reviewers who reviewed them individually. If a record was screened as positive, the two physicians independently reviewed it. The uncertain cases were reanalyzed by reviewers, and if necessary, by a third reviewer (MTM). After screening, criteria-positive clinical records advanced toward the second-stage of the review and the modular revision form 2 (RF2) was completed. In this stage, each record that was positive for one or more criteria was reviewed independently by two physicians (LP and $A B)$. After reviewing the clinical records, the two reviewers compared assessments to see if they agreed for the presence or absence of an AE. If the two reviewers did not agree, they discussed their differences, as in stage 1, and tried to reach an agreement. If the disagreement persisted after this comparison, the folder was submitted to the person responsible for the operational unit, and that person made the final decision. An additional file shows the Modular Revision Forms 1 and 2 in detail [see Additional file 1].

Regarding the association between incidence and organizational factors, four main indicators were taken into account: 1) length of stay, which was considered as an indicator of exposure; 2) type of admission which was an organizational factor linked to planning skills; 3) referral source which was an indicator of levels of coordination between the referral source of patient; 4) and unit of discharge, which was a structural indicator of the organizational context in which the $\mathrm{AE}$ occurred.)

No identifiable human data were used for this study. The data set used in the study is not openly available.

\section{Statistical analysis}

Descriptive statistics were performed to describe a study of population characteristics. A univariable analysis was performed to assess the relationships between AEs and independent variables according to the following: age ( $<1$ years; $1-15$ years; $16-44$ years; $45-64$ years; $\geq 65$ years), gender, residence (Lazio region or outside), nationality (Italian, foreign), marital status (single, married, separated, divorced, widowed), admission referral source (emergency department of the same hospital, other unit in the same 
hospital, different Hospital, specialist), admission type (elective, emergency or compulsory medical treatment), discharge unit (clinical ward, surgery ward, Intensive Care Unit - ICU), length of stay, and the Charlson Index. Chi square and Mann Whitney tests were used to perform the univariable analyses.

Variables whose p-value was less than 0.25 at the univariable analyses were entered a backward stepwise logistic regression model. An additive model was used to perform the analysis. Model goodness of fit was assessed through Hosmer and Lemeshow statistics. The results were shown in terms of Odds Ratio and 95\% Confidence Intervals (95\% CI).

In order to control for confounding related to comorbidity, the Charlson Index [27] was used. The Index was calculated according to the algorithms developed by Quan et al. [28], and by looking at Enhanced ICD-9-CM Coding in primary and secondary diagnoses. The Charlson Index was calculated by using STATA software version 9.0.

All of the other statistical analyses were conducted by using the statistical software SPSS version 12.0. Statistical significance was set at $\mathrm{p}=0.05$.

The paper follows the STROBE guidelines for reporting of observational studies [29]. An additional file shows the completed STROBE checklist [see Additional file 2].

\section{Ethics statement}

Approval of the ethics committee was not required for the study because the Italian legislation (law 211/2003) attains to clinical research studies and does not provide statements on observational studies on routine collected, anonymous data. Data were extracted from routinely collected administrative databases and there was no need to obtain additional data from individual patients. The interventions under study were performed in ordinary or "natural" conditions, irrespective from the conduct of the present study. Because this was an observational retrospective study, patients had already been treated when the study protocol was written. Data linkage was performed by the team directly involved in patients' care using numerical codes. For the present study, researchers had access only to an anonymous dataset, which ensured patients' privacy. For these reasons, no personal informed consent to the present analysis was requested from study participants. The permission to medical records consultation was given by Medical Directions of hospitals involved in the study.

\section{Results}

A total of 1,501 records were reviewed: 1,415 (94.3\%) patients were Italian. The mean age of patients was 60 years (Standard Deviation: 19). One hundred and twenty-one records $(8.1 \%)$ passed the first step of review process. Out of 121, 46 (3.3\%) were judged to be AEs at the end of the second step review. Characteristics of all records are shown in Table 1.

The univariable analysis showed that AEs were more common in patients with a longer length of stay, and in patients admitted to the hospital emergency. In fact, among all patients who experienced AEs, 36 (78.2\%) were admitted to emergency, vs 10 (21.7\%) admitted in election In patients coming from the emergency department of the same hospital as well as from other hospitals who experienced AEs, in fact among all patients experienced AEs, 32 (69.7\%) were admitted from the Emergency Department, 10 (21.7\%) from a specialists, and 4 (8.7\%) came from other hospitals (Table 2).

In regards to the unit of discharge, 4 (8.7\%) patients, which experienced an AE, were discharged from ICU and 9 (19,6\%) from surgical wards (Table 2). The length of stay was associated to AEs also (Table 2).

Patients aged at age 65 or older showed a higher frequency of AEs than those younger.

All these variables, together with age, gender, residence, marital status and the Charlson Index were entered in the multivariable regression model. The final model is shown in Table 3 and demonstrates that admission in emergency was associated to a higher risk for AE (OR 3.47, 95\% CI 1.60-7.53) as well the length of stay (OR 1.03, 95\% CI 1.01-1.04) and the discharge from surgery wards and ICU (OR 2.29, 95\% CI 1.00-5.21 and 4.80, 95\% CI 1.47-15.66 respectively).

\section{Discussion}

This study showed that $3.3 \%$ of patients admitted to hospital experienced an AE. There is high variability of the phenomenon, proved by the higher values of prevalence showed in several studies, ranging from $3 \%$ to $17 \%$ in hospitalized patients [1,2,5,6,12,15,19-21,23,30,31].

Our findings are in line with those reported in the Harvard Medical Practice Study [1] and in a recent work dealing with AEs in Dutch hospitals [17].

The incidence of AEs reported in this study was also lower than the overall $5.2 \%$ average which was yielded by a recent Italian multicenter study [32].

As far as risk factors for AEs, in our study, they were associated with length of stay, type of admission, referral source, and discharge unit.

With respect to length of stay, our study showed an association with AEs, in fact, for each incremental day of hospital stay, the related risk was increased by $3 \%$. This result is in line with the international literature, and it might be explained by a prolonged exposure to risk factors $[3,12,14,18]$.

Regarding type of admission, among all patients who experienced AEs, 78.2\% were admitted in emergency. This date, in contrast with the finding previously reported by Zegers et al. [3] could be due to the overcrowding of 
Table 1 Figure of selected inpatients ordinary admissions

\begin{tabular}{|c|c|c|}
\hline Variable & $\begin{array}{l}\text { Absolute } \\
\text { frequency }\end{array}$ & $\%$ \\
\hline \multicolumn{3}{|l|}{ Passage to RF2 } \\
\hline No & 1,380 & 91.9 \\
\hline YES & 121 & 8.1 \\
\hline Number of adverse events & 46 & 3.3 \\
\hline \multicolumn{3}{|l|}{ Classes of age } \\
\hline$<1$ year & 6 & 0.4 \\
\hline $1-15$ years & 5 & 0.3 \\
\hline $16-44$ years & 353 & 23.5 \\
\hline $45-64$ years & 392 & 26.1 \\
\hline$\geq 65$ years & 745 & 49.6 \\
\hline \multicolumn{3}{|l|}{ Gender } \\
\hline Male & 793 & 52.8 \\
\hline Female & 708 & 47.2 \\
\hline \multicolumn{3}{|l|}{ Lenght of stay for unit of discharge } \\
\hline \multicolumn{3}{|l|}{ (median and interquartile range) } \\
\hline Medical wards & $5(7)$ & \\
\hline Surgical wards & $7(10)$ & \\
\hline Intensive Care Unit & $18(32)$ & \\
\hline \multicolumn{3}{|l|}{ Type of admission } \\
\hline Elective & 641 & 42.8 \\
\hline Mandatory compulsory obligatory & 9 & 0.6 \\
\hline Emergency & 851 & 56.7 \\
\hline \multicolumn{3}{|l|}{ Referral source } \\
\hline Different mode from ordinary admission & 4 & 0.3 \\
\hline Emergency Department of the same hospital & 832 & 55.4 \\
\hline General Practicioner or Specialist & 636 & 42.4 \\
\hline Transfered form other facility & 29 & 1.9 \\
\hline \multicolumn{3}{|l|}{ Discharge unit } \\
\hline Medical ward & 1,186 & 79.0 \\
\hline Surgical ward & 292 & 19.5 \\
\hline Intensive Care Unit & 23 & 1.5 \\
\hline \multicolumn{3}{|l|}{ Residence } \\
\hline Other Italian Region & 77 & 5.1 \\
\hline Lazio Region & 1,424 & 94.9 \\
\hline \multicolumn{3}{|l|}{ Citizenship } \\
\hline Italian & 1,415 & 94.3 \\
\hline Foreign & 86 & 5.7 \\
\hline \multicolumn{3}{|l|}{ Marital status } \\
\hline Not Married & 292 & 19.5 \\
\hline Married & 939 & 62.6 \\
\hline Separatoied & 44 & 2.9 \\
\hline Divorced & 38 & 2.5 \\
\hline
\end{tabular}

Table 1 Figure of selected inpatients ordinary admissions (Continued)

\begin{tabular}{lll}
\hline Widow & 188 & 12.5 \\
Age (mean and standard deviation) & $60(19)$ & \\
$\begin{array}{l}\text { Charlson Index (median and interquartile } \\
\text { range) }\end{array}$ & $0(1)$ &
\end{tabular}

emergency patients. Indeed, as shown in the study of Ackroyd-Stolarz and colleagues, a prolonged stay in the emergency department is associated with an increased risk of any single AE (OR 1.03, 95\% CI 1.004 to 1.05) [33]. Overcrowding in emergency departments is also a common phenomenon in Italian hospitals and could be mainly due to a shortage of available hospital beds, which results in prolonged emergency department stays for patients who need emergency admission [34].

Furthermore, Källberg et al. reported that the emergency department environment was described as complex, dynamic, and vulnerable to medical errors. In particular, the emergency department, in relation to communication, competence, triage, accessibility, and medication management, was identified as a possible risk area [35].

In regards to the referral source in the present work, there was no association with AEs, and that could be due to the adequate coordination mechanisms between the referral source of patients and the unit of discharge.

With respect to the discharge unit in our study, 71.7\% of AEs were observed in medical wards even though a statistical significant association between the discharge unit and $\mathrm{AE}$ was shown only for surgical wards and ICU. As far as surgical wards this results are coherent with literature [12], and these could be mainly due to human factors [17]. As for ICU, several studies reported a high incidence of AEs ranging from 6.9 to 39.2\% [36-44]. Moreover, the incidence of adverse events, according to Silberman et al., is proportional to the duration of ICU stay [45].

Relative to several intrinsic risk factors, the high frequency of AEs in patients admitted to ICU suggests that patient vulnerability could play a major role in generating AEs $[3,14,18,19,30]$. However, our study doesn't show any association with comorbidity assessed by the Charlson Index.

The Charlson Index allowed an adjustment of the risk of AEs for comorbidity, and it relied on the evaluation of ICD-9 codes in primary and secondary diagnoses in the medical charts. In our study, we were able to conclude that, even if an underestimation of patient vulnerability was plausible, comorbidity did not have a great impact on the occurrence of AEs [14]. Notwinstanding further studies showed an association between the Charslon Index and AEs even if the methods for Charlson computation were different from ours [3]. Therefore severity 
Table 2 Findings of univariable analysis

\begin{tabular}{|c|c|c|c|}
\hline \multicolumn{4}{|l|}{ Univariable analysis } \\
\hline Variable & Adverse events no & Adverse events yes & $p$ \\
\hline \multicolumn{4}{|l|}{ Age } \\
\hline$<1$ year & $6(0.4 \%)$ & $0(0 \%)$ & \multirow[t]{5}{*}{0.641} \\
\hline $1-15$ years & $5(0.3 \%)$ & $0(0 \%)$ & \\
\hline $16-44$ years & $346(23.8 \%)$ & 7 (15.2\%) & \\
\hline $45-64$ years & $380(26.1 \%)$ & $12(26.1 \%)$ & \\
\hline$\geq 65$ years & $718(49.3 \%)$ & $27(58.7 \%)$ & \\
\hline \multicolumn{4}{|l|}{ Gender } \\
\hline Male & $766(52.6 \%)$ & $27(58.7 \%)$ & \multirow[t]{2}{*}{0.418} \\
\hline Female & $689(47.4 \%)$ & $19(41.3 \%)$ & \\
\hline \multicolumn{4}{|l|}{ Residence } \\
\hline Other Italian Region & 77 (5.3\%) & $0(0 \%)$ & \multirow[t]{2}{*}{0.109} \\
\hline Lazio & 1378 (94.7\%) & $46(100 \%)$ & \\
\hline \multicolumn{4}{|l|}{ Citizenship } \\
\hline Italian & 1370 (94.2\%) & 45 (97.8\%) & \multirow[t]{2}{*}{0.292} \\
\hline Foreign & $85(5.8 \%)$ & $1(2.2 \%)$ & \\
\hline \multicolumn{4}{|l|}{ Marital status } \\
\hline Not married & $286(19.7 \%)$ & $6(13.0 \%)$ & \multirow[t]{5}{*}{0.115} \\
\hline Married & $914(62,8 \%)$ & $25(54.3 \%)$ & \\
\hline Separated & $41(2.8 \%$ & $3(6.5 \%)$ & \\
\hline Divorced & $36(2.5 \%)$ & $2(4.3 \%)$ & \\
\hline Widow & $178(12.2 \%)$ & $10(2.7 \%)$ & \\
\hline Lenght of stay & $6(7)$ & $15(20)$ & $<0.001$ \\
\hline \multicolumn{4}{|l|}{ (median and interquartile range) } \\
\hline \multicolumn{4}{|l|}{ Type of admission (1499) } \\
\hline Elective & $629(43.3 \%)$ & $10(21.7 \%)$ & \multirow[t]{2}{*}{$<0.001$} \\
\hline Emergency & $824(56.7 \%)$ & $36(78.2 \%)$ & \\
\hline \multicolumn{4}{|l|}{ Referral source (1499) } \\
\hline Different mode from ordinary admission & $4(0.3 \%)$ & $0(0 \%)$ & \multirow[t]{4}{*}{$<0.001$} \\
\hline Emergency Department of the same hospital & $800(55.1 \%)$ & $32(69.7 \%)$ & \\
\hline General Practicioner or Specialist & $624(42.3 \%)$ & $10(21.7 \%)$ & \\
\hline Transfered form other facility & $25(1.7 \%)$ & $4(8.7 \%)$ & \\
\hline \multicolumn{4}{|l|}{ Discharge unit } \\
\hline Medical ward & $1153(79.2 \%)$ & $33(71.7 \%)$ & \multirow[t]{3}{*}{$<0.001$} \\
\hline Surgical ward & $283(19.5 \%)$ & $9(19.6 \%)$ & \\
\hline Intensive Care Unit & $19(1.3 \%)$ & $4(8.7 \%)$ & \\
\hline Charlson Index & $0(1)$ & $0(1)$ & 0.99 \\
\hline (median and interquartile range) & & & \\
\hline
\end{tabular}

of comorbidity could not be a main factor in developing AEs. On the other hand, organizational aspects could be responsible for the increased risk of AEs in particular wards. The study of Aranaz-Andrés reported a relation between the occurrence of AEs and the presence of extrinsic risk factors, such as urinary catheter, peripheral venous catheter, peripherally inserted central venous catheter, central venous catheter, parenteral nutrition, enteral nutrition, nasogastric tube, oesophagogastric percutaneous catheter, tracheostomy, mechanic ventilation or immunosuppression therapy [18]. Indeed, beyond patient vulnerability, the complexity of health-care 
Table 3 Findings of multivariable analysis

\begin{tabular}{lll}
\hline Variable & OR & Cl (95\%) \\
\hline Age & 1 & \\
$0-64$ anni & 1.40 & $0.75-2.61$ \\
$\geq 65$ anni & & \\
Gender & 1 & $0.41-1.42$ \\
Male & 0.77 & $1.01-1.04$ \\
Female & 1.03 & \\
Length of stay & & \\
Type of admission & 1 & $1.60-7.53$ \\
Elective & 3.47 & \\
Emergency & & $1.00-5.21$ \\
Discharge unit & 1 & $1.47-15.66$ \\
Medical ward & 2.29 & $0.74-1.16$ \\
Surgical ward & 4.80 & \\
ICU & 0.93 & \\
Charlson Index &
\end{tabular}

Hosmer and Lemeshow Test, Chi-square 5.368, $p=0.718$.

services also appears to be associated with the development of AEs [18], and prevention also depends on the ability of the hospital environment to adapt to the variety of situations in which AEs occur [2]. Furthermore, a prolonged hospital stay, sure enough, could produce a higher exposure to organizational factors.

In view of what has been said, the use of a double-step tool for the detection of AEs, in association with a monitoring system of organizational factors adjusted for the Charlson index, could provide a useful contribution to clinical risk management.

Our study has some limitations. First of all, AEs were identified by means of a review process that relied on information enclosed in medical records, and this could produce a possible underestimation of AEs $[18,16]$. The same reason could be responsible for a misclassification of the unit in which AEs occurred. In fact, our analysis accounted for the unit of discharge and the AEs that were attributed to it. Furthermore, it is probable that the AEs occurred in a different unit if the patient moved from one ward to another during the stay. Anyway it's plausible that misclassification was not differential being only a dilution of risk possible.

Our study has several strengths. It was performed at the hospital level, which made it possible to have a thorough overview of AEs that occur in one year. Furthermore, the methodology used to identify AEs was based on a two-steps approach, which allowed strengthening the assessment. Two researchers were involved in the second step of the review process, which enabled the identification of AEs. The screening step was performed by two researchers on the first $10 \%$ of the clinical records with optimal agreement. Moreover, since the sampling was random, clinical records were not chosen with respect to their complexity. Another strength was related to the method used to account for comorbidity in the Charlson Index, which allowed us to tackle the problem of confounding that could interfere with the impact of organizational factors on AEs. Furthermore, Charlson index may be considered a good proxy of hospital case mix.

\section{Conclusions}

In conclusion on the basis of our results, it appears that organizational characteristics, taking into account the adjustment for comorbidity, are the main factors responsible for AEs while patient vulnerability played a minor role.

Hospitals should implement risk management programs and address patients' safety issues. From this viewpoint, it is fundamental to promote a continuous and timely evaluation of AEs with respect to their frequency, risk factors and costs.

\section{Additional files}

Additional file 1: Modular Revision Forms 1 and 2. The Modular Revision Forms are tools, adapted by those of Vincent et al. [6], used by reviewers to screen clinical records to detect AEs.

Additional file 2: STROBE checklist. STROBE checklist for reporting observational research, filled in relation to the present study.

\section{Competing interests}

The authors declare that they have no competing interest.

\section{Authors' contributions}

LS participated in the design of the study and provided data. CDW and AMF performed the statistical analysis and helped to draft the manuscript. $A B$ and LP screened and assessed clinical records. MTM contributed in the assessment of clinical records when the other reviewers were not agree. WR revised critically the final version of the manuscript. GD conceived the study, participated in its design and coordination and helped to draft the manuscript. All authors read and approved the final manuscript.

\section{Acknowledgements}

We thank Joan C. Stevenson for the linguistic revision.

\section{Author details}

${ }_{1}^{1}$ General Direction, San Filippo Neri Hospital Trust, Via G. Martinotti 20, Rome 00135, Italy. ${ }^{2}$ Department of Public Health, Catholic University of Sacred Heart, L.go Francesco Vito 1, Rome 00168, Italy. ${ }^{3}$ Medical Direction, San Filippo Neri Hospital Trust, Via G. Martinotti 20, Rome 00135, Italy.

Received: 18 February 2014 Accepted: 20 August 2014

Published: 27 August 2014

\section{References}

1. Brennan TA, Leape LL, Laird NM, Hebert L, Localio AR, Lawthers AG, Newhouse JP, Weiler PC, Hiatt HH, Harvard Medical Practice Study I: Incidence of adverse events and negligence in hospitalized patients: results of the Harvard Medical Practice Study I. N Engl J Med 1991, 324(6):370-376.

2. Michel P, Quenon $J$, De Sarasqueta AM, Scemanna O: Comparison of three methods for estimating rates of adverse events and rates of preventable adverse events in acute care hospitals. BMJ 2004, 328(7433):199. 
3. Zegers M, De Bruijne MC, Spreeuwenberg P, Wagner C, Van Der Wal G, Groenewegen PP: Variation in the rates of adverse events between hospitals and hospital departments. Int I Qual Health Care 2011, 2:126-133.

4. Michel P, Quenon JL, Djihoud A, Tricaud-Vialle S, De Sarasqueta AM: French national survey of inpatient adverse events prospectively assessed with ward staff. Qual Saf Health Care 2007, 16:369-377.

5. Thomas EJ, Studdert DM, Burstin HR, Orav EJ, Zeena T, Williams EJ, Howard KM, Weiler PC, Brennan TA: Incidence and types of adverse events and negligent care in Utah and Colorado. Med Care 2000, 38:261-271.

6. Vincent C, Neale G, Woloshynowych M: Adverse events in British hospitals: preliminary retrospective record review. BMJ 2001, 322:517-519.

7. World alliance for patient safety forward programme. 2005 [http://www.who.int/patientsafety/en/brochure_final.pdf]

8. World Health Organization. 10 facts on patient safety. [http://www.who. int/features/factfiles/patient_safety/en/index.html]

9. World Health Organization: Global Priorities for Patient Safety Research. Better knowledge for safer care. [http://whqlibdoc.who.int/publications/ 2009/9789241598620_eng.pdf]

10. Schimmel EM: The hazards of hospitalization. Ann Intern Med 1964 60:100-110.

11. Steel K, Gertman PM, Crescenzi C, Anderson J: latrogenic illness on a general medical service et a university hospital. N Engl J Med 1981, 304:638-642.

12. Baker RG, Norton PG, Flintoft V, Blais R, Brown A, Cox J, Etchells E, Ghali WA, Hébert P, Majumdar SR, O'Beirne M, Palacios-Derflingher L, Reid RJ, Sheps S, Tamblyn R: The Canadian Adverse Events Study: the incidence of adverse events among hospital patients in Canada. JAMC 2004, 170:1678-1686.

13. Forster AJ, Asmis TR, Clark HD, Al Saied G, Code CC, Caughey SC, Baker K, Watters J, Worthington J, Van Walraven C, Ottawa Hospital Patient Safety Study: Ottawa Hospital Patient Safety Study: incidence and timing of adverse events in patients admitted to a Canadian teaching hospital. Can Med Assoc J 2004, 170:1235-1240

14. Martins M, Travassos C, Mendes W, Pavão AL: Hospital deaths and adverse events in Brazil. BMC Health Serv Res 2011, 11:223.

15. Schioler T, Lipczak H, Pedersen BL, Mogensen TS, Bech KB, Stockmarr A, Svenning AR, Frolich A, Danish Adverse Event Study: Incidence of adverse events in hospitals: a retrospective study of medical records. Ugeskr Laeger 2001, 163:5370-5378.

16. Zegers M, De Bruijne MC, Wagner C, Groenewegen PP, Waaijman R, van der Wal G: Design of a retrospective patient record study on the occurrence of adverse events among patients in Dutch hospitals. BMC Health Serv Res 2007, 7:27

17. Zegers M, De Bruijne MC, De Keizer B, Merten H, Groenewegen PP, van de Wal G, Wagner C: The incidence, root-causes, and outcomes of adverse events in surgical units: implication for potential prevention strategies. Patient Saf Surg 2011, 5:13.

18. Aranaz-Andrés JM, Aibar- Remòn C, Vitaller-Burillo J, Ruiz-López P, Limón-Ramírez $R$ Terol-García E, ENEAS work group: Incidence of adverse events related to health care in Spain: results of the Spanish National Study of Adverse Events. $J$ Epidemiol Community Health 2008, 62(12):1022-1029.

19. Aranaz-Andrés JM, Aibar- Remòn C, Vitaller-Burillo J, Requena-Puche J, Terol-García E, Kelley E, Gea-Velazquez de Castro MT, ENEAS work group: Impact and preventability of adverse events in Spanish public hospitals: results of the Spanish National Study of Adverse Events (ENEAS). Int $J$ Qual Health Care 2009, 21(6):408-414.

20. Soop M, Fryksmark U, Koster M, Haglund B: The incidence of adverse events in Swedish hospitals: a retrospective medical record review study. Int I Qual Health Care 2009, 21(4):285-291.

21. Wilson RM, Runciman WB, Gibberd RW, Harrison BT, Newby L, Hamilton JD: The quality in Australian health-care study. Med J Aust 1995, 163:458-471.

22. Davis P, Lay-Yee R, Schug S, Briant R, Scott A, Johnson S, Bingley W: Adverse events regional feasibility study: indicative findings. N Z Med J 2001, 114:203-205.

23. Davis $P$, Lay-Yee R, Briant R, Ali W, Scott A, Schug S: Adverse events in New Zealand public hospital I: occurrence and impact. N Z Med J 2002, 115(1167):U271.

24. Smits $M$, Zegers $M$, Groenewegen $P$, Timmermans $D R$, Zwaan $L$, van der Wal $G$, Wagner C: Exploring the causes of adverse events in hospitals and potential prevention strategies. Qual Saf Health Care 2010, 19:e5.
25. Hayajneh YA, AbuAIRub RF, Almakhzoomy IK: Adverse events in Jordanian hospitals: types and causes. Int J Nurs Pract 2010, 16(4):374-380.

26. Ouellette JR, Small DG, Termuhlen PM: Evaluation of Charlson-age comorbidity index as predictor of morbidity and mortality in patients with colorectal carcinoma. J Gastrointest Surg 2004, 8(8):1061-1067.

27. Charlson ME, Pompei P, Ales KL, Mackenzie CR: A new method of classifying prognostic comorbidity in longitudinal studies: development and validation. J Chronic Dis 1987, 40:373-383.

28. Quan $H$, Sundarajan V, Halfon P, Fong A, Burnand B, Luthi JC, Saunders LD, Beck CA, Feasby TE, Ghali WA: Coding algorithms for defining comorbidities in ICD-9-CM and ICD-10 administrative data. Med Care 2005, 43(11):1130-1139.

29. Von Elm E, Altman DG, Egger M, Pocock SJ, Gøtzsche PC, Vandenbroucke JP: STROBE initiative: the Strengthening the Reporting of Observational Studies in Epidemiology (STROBE) statement: guidelines for reporting observational studies. J Clin Epidemiol 2008, 61(4):344-349.

30. Davis P, Lay-Yee R, Briant R, Scott A, Schug S: Adverse events in New Zealand public hospitals II: preventability and clinical context. N Z Med J 2003, 116:U624.

31. Leape LL, Brennan TA, Laird N, Lawthers AG, Localio AR, Barnes BA, Hebert $L$, Newhouse JP, Weiler PC, Hiatt $H$ : The nature of adverse events in hospitalized patients: results of the Harvard Medical Practice Study II. N Engl J Med 1991, 324(6):377-384.

32. Tartaglia R, Albolino $S$, Bellandi $T$, Bianchini E, Biggeri A, Fabbro $G$, Bevilacqua L, Dell'erba A, Privitera G, Sommella L: Adverse events and preventable consequences: retrospective study in five large Italian hospitals. Epidemiol Prev 2012, 36(3-4):151-161.

33. Ackroyd-Stolarz S, Read Guernsey J, Mackinnon NJ, Kovacs G: The association between a prolonged stay in the emergency department and adverse events in older patients admitted to hospital: a retrospective cohort study. BMJ Qual Saf 2011, 20(7):564-569.

34. Fornero G, Arione R, Fiandra U, Rapellino M, Bono A, Moiraghi C, Gianino MM: Overcrowding in emergency departments: the case of the San Giovanni Battista (Molinette) university hospital in Turin (Italy). Ig Sanita Pubbl 2011, 67(5):541-552.

35. Källberg AS, Göransson KE, Östergren J, Florin J, Ehrenberg A: Medical errors and complaints in emergency department care in Sweden as reported by care providers, healthcare staff, and patients - a national review. Eur J Emerg Med 2013, 20(1):33-38.

36. Valentin A, Capuzzo M, Guidet B, Moreno RP, Dolanski L, Bauer P, Metnitz PG, Research Group on Quality Improvement of European Society of Intensive Care Medicine; Sentinel Events Evaluation Study Investigators: Patient safety in intensive care: results from the multinational Sentinel Events Evaluation (SEE) study. Intensive Care Med 2006, 32(10):1591-1598.

37. Pagnamenta A, Rabito G, Arosio A, Perren A, Malacrida R, Barazzoni F, Domenighetti $\mathrm{G}$ : Adverse event reporting in adult intensive care units and the impact of a multifaceted intervention on drug-related adverse events. Ann Intensive Care 2012, 2(1):47.

38. Rothschild JM, Landrigan CP, Cronin JW, Kaushal R, Lockley SW, Burdick E, Stone PH, Lilly CM, Katz JT, Czeisler CA, Bates DW: The critical care safety study: the incidence and nature of adverse events and serious medical errors in intensive care. Crit Care Med 2005, 33(8):1694-1700.

39. Harris CB, Krauss MJ, Coopersmith CM, Avidan M, Nast PA, Kollef MH, Dunagan WC, Fraser VJ: Patient safety event reporting in critical care: a study of three intensive care units. Crit Care Med 2007, 35(4):1068-1076.

40. Garrouste Orgeas M, Timsit JF, Soufir L, Tafflet M, Adrie C, Philippart F, Zahar JR, Clec'h C, Goldran-Toledano D, Jamali S, Dumenil AS, Azoulay E, Carlet J, Outcomerea Study Group: Impact of adverse events on outcomes in intensive care unit patients. Crit Care Med 2008, 36(7):2041-2047.

41. Graf J, Von den Driesch A, Koch KC, Janssens U: Identification and characterization of errors and incidents in a medical intensive care unit. Acta Anaesthesiol Scand 2005, 49:930-939.

42. Vriesendorp TM, DeVries JH, Van Santen S, Moeniralam HS, De Jonge E, Roos YB, Schultz MJ, Rosendaal FR, Hoekstra JB: Evaluation of short-term consequences of hypoglycemia in an intensive care unit. Crit Care Med 2006, 34:2714-2718. 
43. Rubins HB, Moskowitz MA: Complications of care in a medical intensive care unit. J Gen Intern Med 1990, 5:104-109.

44. Giraud T, Dhainaut JF, Vaxelaire JF, Joseph T, Journois D, Bleichner G, Sollet JP, Chevret S, Monsallier JF: latrogenic complications in adult intensive care units: a prospective two-center study. Crit Care Med 1993, 21:40-51.

45. Silberman $S$, Bitran D, Fink $D$, Tauber $R$, Merin O: Very prolonged stay in the intensive care unit after cardiac operations: early results and late survival. Ann Thorac Surg 2013, 96(1):15-21.

doi:10.1186/1472-6963-14-358

Cite this article as: Sommella et al:: The incidence of adverse events in an Italian acute care hospital: findings of a two-stage method in a retrospective cohort study. BMC Health Services Research 2014 14:358

\section{Submit your next manuscript to BioMed Central and take full advantage of:}

- Convenient online submission

- Thorough peer review

- No space constraints or color figure charges

- Immediate publication on acceptance

- Inclusion in PubMed, CAS, Scopus and Google Scholar

- Research which is freely available for redistribution 